\title{
Comment on: Evans JMM, Ogston SA, Emslie-Smith A, Morris AD (2006) Risk of mortality and adverse cardiovascular outcomes in type 2 diabetes: a comparison of patients treated with sulfonylureas and metformin. Diabetologia 49:930-936
}

\author{
J. A. Tayek \\ Received: 20 June 2006 / Accepted: 12 July 2006 / Published online: 6 September 2006 \\ (C) Springer-Verlag 2006
}

To the Editor:

In their recent article in Diabetologia, Evans et al. demonstrated that the unadjusted risk of cardiovascular mortality with sulfonylurea monotherapy was $3.71 \mathrm{com}$ pared with metformin monotherapy [1]. After adjusting for differences between groups, the relative risk of cardiovascular mortality was 1.70 (95\% CI 1.18-2.45). Likewise, in the University Related Diabetes Project, cardiovascular mortality was $12.7 \%$ in the tolbutamide monotherapy group, as compared with $4.9 \%$ in the placebo-treated diabetic group [2] - an unadjusted risk of 2.6. In another study, the adjusted risk of mortality was 2.1 with tolbutamide or chlorpropamide monotherapy, and 1.3 with glibenclamide (known as glyburide in the USA and Canada) monotherapy [3], similar to the figure of 1.22 reported for glibenclamide monotherapy in a recent study [4]. With regard to cardiovascular mortality, monotherapy with glibenclamide was associated with a significant adjusted risk of 1.37 [3].

Evans et al. also demonstrated that the use of metformin with a sulfonylurea is associated with an approximately two-fold increased adjusted risk of cardiovascular mortality as compared with metformin alone [1]. In 1998, a UK prospective diabetes study demonstrated that the addition of a sulfonylurea (glibenclamide or chlorpropamide) to metformin therapy increased mortality by $60 \%$ (3.0 vs 1.9 per 100 patient-years; $p<0.05$ ) [5]. A similar 1.63-fold increase in mortality was seen in diabetic patients given combination therapy with a sulfonylurea plus metformin compared with

J. A. Tayek $(\triangle)$

Harbor-UCLA Medical Center,

1000 W. Carson, Box 428, Torrance, CA 90509, USA

e-mail: jtayek@ladhs.org sulfonylurea alone [6]. Of interest was the fact that aggressive therapy with metformin alone reduced mortality compared with aggressive therapy with conventional medications ( 1.3 vs $2.1 \%$ per 100 patient-years) [5]. In this trial, approximately one-third of the patients given conventional treatment were using glibenclamide or chlorpropamide. In a fourth trial, mortality was increased 1.53 -fold in patients given the combination of glibenclamide and metformin [4].

The only published study to investigate whether there are different cardiovascular risks associated with the different sulfonylureas is that conducted by Monami et al. [7]. They reported that patients have a higher mortality rate when given glibenclamide combined with metformin than when combined with glimepiride, glicazide or repaglinide. In this study, 2,002 diabetic patients were followed over a 31 -month period and mortality rates determined. The annual mortality rate associated with metformin plus glibenclamide was significantly greater than that associated with metformin plus repaglinide ( 8.7 vs $3.1 \%$; $p=0.002$ ). Likewise, therapy with metformin plus gliclazide was associated with a significantly lower annual mortality rate than metformin plus glibenclamide ( $2.1 \mathrm{vs} 8.7 \% ; p=0.001)$. Most impressively, there was a 22 -fold reduction in mortality if metformin was given with glimepiride rather than with glibenclamide ( 0.4 vs $8.7 \% ; p<0.0001)$. Since the study by Evans et al. [1] demonstrated increased mortality associated with sulfonylureas, both alone and in combination with metformin, it would be helpful to know whether different sulfonylureas were used and, if so, whether there were any differences in mortality between them.

Interestingly, the drug concentration at which $50 \%$ of the $\mathrm{K}_{\text {ATP }}$ channel SUR receptor is activated is approximately 1,000-fold lower with glibenclamide than with repaglinide 
[8]. While the usual dosing of glibenclamide is ten times that of repaglinide, the resultant 100 -fold increase in SUR binding activity of glibenclamide at the SUR receptor [8] may explain why glibenclamide, like the first-generation sulfonylureas, has been associated with an increase in cardiovascular mortality. Perhaps it would be wise for physicians to stop using all sulfonylureas until we have confirmatory data that some are safer than others.

\section{References}

1. Evans JMM, Ogston SA, Emslie-Smith A, Morris AD (2006) Risk of mortality and adverse cardiovascular outcomes in type 2 diabetes: a comparison of patients treated with sulfonylureas and metformin. Diabetologia 49:930-936

2. Goldner MG, Knatterud GL, Prout TE for the University Group Diabetes Program (1971) Effects of hypoglycemia agents on vascular complications in patients with adult-onset diabetes. JAMA 218:1400-1410
3. Simpson SH, Mujamdar SR, Tsuyuki RT, Eurich DT, Johnson JA (2006) Dose-response relation between sulfonylurea drugs and mortality in type 2 diabetes mellitus: a population-based cohort study. CMAJ 174:169-174

4. Fisman EZ, Tenenbaum A, Boyko V (2001) Oral antidiabetic treatment in patients with coronary disease: time-related increase mortality on combined glyburide/metformin therapy over a 7.7-year follow-up. Clin Cardiol 24:151-158

5. UK Prospective Diabetes Study (UKPDS) Group (1998) Effect of intensive blood-glucose control with metformin on complications in overweight patients with type 2 diabetes (UKPDS 34). Lancet 352:854-865. Erratum in: Lancet 352:1558

6. Olsson J, Lindberg G, Gottsater M et al (2000) Increased mortality in type 2 diabetic patients using sulphonylurea and metformin in combination: a population-based observational study. Diabetologia 43:558-560

7. Monami M, Luzzi C, Lamanna C et al (2006) Three-year mortality in diabetic patients treated with different combinations of insulin secretagogues and metformin. Diabetes Metab Res Rev 22 (in press). DOI 10.1002/dmrr.642

8. Hu S, Wang S, Fanelli B et al (2000) Pancreatic $\beta$-cell $\mathrm{K}_{\text {ATP }}$ channel activity and membrane-binding studies with nateglinide: a comparison with sulfonylureas and repaglinide. J Pharm Exper Therap 293:444-452 